\title{
A Stress Intensity Function for FCG Analyses in Metals
}

\author{
Daniel Kujawski ${ }^{1}$ \\ ${ }^{1}$ Affiliation not available
}

March 3, 2021

\begin{abstract}
This paper presents a damaging stress intensity function $\mathrm{K}_{\mathrm{d}}$ for analyses of R-ratio effects on fatigue crack growth (FCG) in metals. The proposed formulation is based on the sum of strain and complementary energy and its role in FCG rate behavior in threshold and Paris region at R-ratios ranging from -2 to 0.97 . It doesn't invoke a crack closure assumption or fitting parameters for $\mathrm{R}<0.5-0.6$. For a high $\mathrm{R}>0.7$ it utilizes an experimentally determine correction factor, which accounts for excessive plastic dissipation in the monotonic plastic zone (MPZ).
\end{abstract}

\section{Hosted file}

SIF function for FCG analysis.pdf available at https://authorea.com/users/399365/articles/ 511923-a-stress-intensity-function-for-fcg-analyses-in-metals 